\title{
Relationship between the Prevalence of ACE1 I/D Polymorphism Genotype II and Covid-19 Morbidity, Mortality in Ukraine and in Some Europe Countries
}

\author{
L. A. Livshits ${ }^{b, *}$, T. A. Harashchenko ${ }^{a}$, T. R. Umanets ${ }^{a}$, D. S. Krasnienkov ${ }^{c}$, \\ O. V. Gorodna ${ }^{b}$, Vl. V. Podolskiy ${ }^{a}$, T. M. Kaminska ${ }^{d}$, V. F. Lapshyn ${ }^{a}$, \\ V. V. Podolskiy ${ }^{a}$, and Yu. G. Antipkin ${ }^{a}$ \\ ${ }^{a}$ State Institution "Institute of Pediatrics, Obstetrics and Gynecology named after Academician O.M. Lukyanova, \\ National Academy of Medical Sciences of Ukraine”, Kyiv, 04050 Ukraine \\ ${ }^{b}$ Institute of Molecular Biology and Genetics National Academy of Sciences of Ukraine, Kyiv, 03143 Ukraine \\ ${ }^{c}$ State Institution "Institute of Gerontology named after Dmitry F. Chebotarev, \\ National Academy of Medical Sciences of Ukraine”, Kyiv, 04114 Ukraine \\ ${ }^{d}$ Kyiv City Children's Clinical Hospital of Infectious Diseases, Kyiv, 04119 Ukraine \\ *e-mail: livshits@edu.imbg.org.ua
}

Received May 2, 2021; revised June 7, 2021; accepted September 1, 2021

\begin{abstract}
Coronavirus disease (COVID-19), which was first recorded in China in December 2019, quickly spread to other countries and in a short period of time, the local outbreak escalated into a pandemic. There are significantly more cases of COVID-19 morbidity and mortality in European countries than in East Asia, where the disease was first detected. Such population differences are unique, especially for SARS-CoV-2 and are due to both socio-behavioral differences and features of the gene pool of the population of different countries. For infectious diseases, such as COVID-19, an important point is the genetic characteristics of individuals, which can determine its resistance or susceptibility to infection. Therefore, studies of the factors of hereditary predisposition to SARS-CoV-2 infection, as well as severity and mortality are extremely relevant. After genotyping among the healthy population of Ukraine and collecting relevant data from some European countries, we determined the correlation between morbidity, mortality from COVID-19 and the prevalence of genotype II (ACE1, I/D polymorphism) in the populations of Ukraine and several European countries. There was a negative correlation between the carrier of genotype II and susceptibility to SARS-CoV-2 infection per one million population $(R=-0.53, p<0.05)$, so individuals with genotype II can be considered more resistant to infection SARS-CoV-2. Further study of the role of allelic variants of the $A C E 1$ gene in the development of severity and complications affected patients of COVID-19, are promising for identified of genetic markers for development of personalized therapy.
\end{abstract}

DOI: $10.3103 / \mathrm{S} 0095452721050054$

\section{INTRODUCTION}

Coronavirus disease (COVID-19) is an acute infectious disease of the respiratory system caused by a novel coronavirus (SARS-CoV-2) and called severe acute respiratory syndrome coronavirus 2 (SARS- $\mathrm{CoV}-2$ ) according to the International Committee on Virus Taxonomy. (Velavan et al., 2020). The disease first became known on December 31, 2019, when the WHO was alerted of the pneumonia cases of unknown etiology detected in Wuhan City, Hubei Province, China. After the first recorded case of this disease in China, the virus quickly spread to other countries in Asia, Central and Northern Europe, and America. In a few weeks, a local outbreak dramatically escalated and became a global pandemic. The World Health Organization declared a Public Health Emergency of
International Concern (PHEIC) on 30 January 2020 (Ren L.L. et al., 2020). On May 1, 2021, the number of infected by SARS-CoV-2 worldwide reached almost 170 million along with 3.5 million deaths.

It is important to note that both the morbidity and mortality of COVID-19 were significantly higher in European countries compared to that in East Asia where the disease has been first detected (Zhu N. et al., 2020). Such population differences are unique for SARS-CoV-2 and have not been observed in either severe respiratory syndrome (SARS) or Middle Eastern respiratory syndrome (MERS), which occurred in 2002 and 2012, respectively. Apart from the sociobehavioral differences between the populations of Europe and East Asia, certain differences in both the virological nature of SARS-CoV-2 and the gene pool 
of the countries in question should be considered. For infectious diseases such as COVID-19, an important point is the genetic characteristics of individuals which can determine resistance or susceptibility of a particular individual to the infection. Therefore, studies of the hereditary predisposition factors with respect to the SARS-CoV-2 infection as well as the severity and mortality are extremely relevant.

Angiotensin-converting enzyme 2 (ACE2) has been identified as a functional receptor for SARS$\mathrm{CoV}-2$ which allows the virus to enter host cells, similar to (SARS) 2002 (Li W. et al., 2003). The study of the molecular interaction between the virus and the host cell receptor is an important step towards understanding the pathogenesis of viral infection and susceptibility to infection in certain individuals. It is worth noting that despite the already studied stable molecular mechanisms of SARS-CoV-2 infection, significant differences in clinical manifestations and course of the disease have been established. This may be related to a circulation of different virus strains in populations as well as genetic characteristics of the infected individual.

Previous studies have modelled the interaction of the virus with different mutant variants of the ACE2 receptor and predicted that genetic variants in the $A C E 2$ gene might affect the individual susceptibility or resistance to SARS-CoV-2, according to the functional role of ACE2 in human pathophysiology. However, given the recent studies of the $A C E 2$ gene coding sequence among 131 SARS-CoV-2 positive individuals, no significant data hasn't obtained in favor of a link between the genetic variants of the $A C E 2$ gene and the susceptibility to infection and/or severity of COVID-19 disease (Novelli A. et al., 2020). It is evident that the penetration of the coronavirus into the cell results in a decrease of amount of active ACE2. Since ACE2 along with ACE1 and renin are the major regulators of the renin-angiotensin system (RAS), a better understanding of this mechanism along with the factors affecting it currently have extremely high importance.

The role of ACE1 is to convert angiotensin I into angiotensin II as well as the metabolism of bradykinin while ACE2 is responsible for converting angiotensin II to angiotensin 1-7. The interaction between ACE1 and ACE2 is reciprocal: when the former is activated the latter is suppressed. This interaction is preserves of physiological homeostasis in the context of RAS. Under the conditions of infection with SARS-CoV-2 virus, angiotensin II in the patient's body is not transformed into angiotensin 1-7 which disrupts the RAS balance. This may also contribute to the development of a severe acute respiratory syndrome (SARS), because of increased vascular permeability (Itoyama S. et al., 2004), incipient apoptosis of endothelial cells (Tiret L. et al., 1992) and alveolar epithelium cells (Zheng H. et al., 2020).
In the 16th intron of the $A C E 1$ gene, there are two allelic variants - I/D (insertion/deletion), 287 nucleotides. ACE II, ID, and DD are the three genotypes of ACE. Different levels of ACE protein are observed in these genotypes. Individuals with Alu (genotype II) have lower ACE levels than individuals with Alu (DD genotype). The intronic Alu polymorphism of the $A C E$ gene directly affects the expression of this gene because the presence of the Alu element in the 16 intron regulates the activity of the ACE gene promoter and serves as a transactivation repressor of RNA polymerase II activity (Rigat B. et al., 1990). Individuals having a homozygous deletion (absence) of Alu repeats (genotype DD) show the highest level of ACE1 protein expression, while individuals that are homozygous for insertions of genotype II demonstrate a lower level of expression. Alu polymorphism in the $A C E$ gene can significantly affect the susceptibility to infection, clinical manifestations, and the course of COVID-19 in many ways.

I/D polymorphism is one of the important factors associated with ACE levels in blood plasma and in body tissues. It was hypothesized that the polymorphism is a very important factor in the context of predicting the course of the disease in patients and the development of personal therapy (Saab Y.B. et al., 2007). Some researchers underline that such an imbalance can lead to fibrosis (Bellone M. et al., 2020) as well as contribute to pro-inflammatory processes by releasing pro-inflammatory mediators: interleukin-6, interleukin-8 (Ned R.M. et al., 2012). Due to the important functional role of the $A C E 1$ gene, altered expression levels of the encoded protein in individuals by I/D polymorphism may be a prerequisite for important pathological processes associated with COVID-19. The goal of the present study was to investigate the relationship between the genotype distribution by polymorphism I/D and COVID-19 morbidity/mortality rates in Ukraine and other European countries.

\section{MATERIALS AND METHODS}

A group of 100 healthy unrelated individuals from different parts of Ukraine participated in the study by informed consent as a population sample. Isolation and purification of DNA from the peripheral blood leukocytes of the individuals in the observed group was performed by a standard phenol-chloroform method using proteinase $\mathrm{K}$. The data on the genotype II distribution by ACE1 polymorphism in different European countries (Hungary, Poland, Slovakia, France, Italy, Spain, Great Britain, Netherlands, Sweden, Denmark, Portugal, Switzerland, Belgium, Germany) were collected from the literature. The data on the number of patients and the number of deaths per one million population in Ukraine were obtained from the Center for Public Health of the Ministry of Health of Ukraine (https://www.phc.org.ua/). For the European countries, the data were collected from The Center for Systems Science and Engineering at Johns Hopkins Uni- 
versity. (https://coronavirus.jhu.edu/map.html) and the webpage (https://ourworldindata.org).

To analyze the I/D polymorphism of the ACE1 gene, the PCR technique with end-point detection was employed. The following sequences of oligonucleotide primers were used:

\section{F 5' CTG GAG AGC CAC TCC CAT CCT TTC T 3' R 5' GAC GTG GCC ATC ACA TTC GTC AGA T 3'}

The synthesis of the oligonucleotide primers was performed by METABION (Munich, Germany) according to a predifined design. A set of Master Mix ready to load kit manufactured by Solis BioDyne (Tartu, Estonia) was used to carry out the polymerase chain reaction. The latter were performed automatically in an iCycler thermocycler, BIO-RAD (Hercules, California, USA). The PCR products were fractionated by gel electrophoresis in $2 \%$ agarose gel and stained with $1 \%$ solution of ethidium bromide (an intercalating DNA dye).

The statistical data analyses were performed using Spearman's rank correlation coefficient $(R)$.

\section{RESULTS}

The I/D polymorphism in the $A C E 1$ gene is the presence (I - Insertions, $490 \mathrm{bp}$ ) or absence (D -Ddeletion, $203 \mathrm{bp}$ ) of the 287 nucleotide in the 16th intron of the $A C E 1$ gene. The results of the analysis of this polymorphism are shown in Fig. 1.

The analysis of allelic variants by $A C E 1$ I/D polymorphism was performed in a group of 100 people from different regions of Ukraine (the mean age was $35 \mathrm{yr}$, men to women ratio was 1:1). The distributions of genotypes and allelic variants of the studied polymorphism is shown in Table 1.

To analyze the relationship between the genotype II incidence and the COVID-19 morbidity/mortality per one million population in Ukraine and some European countries, the data on the genotype prevalence II with respect to $A C E 1 \mathrm{I} / \mathrm{D}$ polymorphism were collected from the previously published literature sources (Table 2).

For each European country, to harmonize the data, morbidity and mortality rates were taken for different periods of the COVID-19 pandemic, namely, when (i) peaks in coronavirus disease were detected in each country and (ii) RT-PCR testing reached 100 per 1000 population. For Ukraine, it is the period from 01.02.21-01.05.21 while for such countries as Hungary, Poland, Slovakia, France, Italy, Spain, Great Britain, the Netherlands, Sweden, Denmark, Portugal, Switzerland, Belgium, Germany it is the period from 23.03.20-23.05.20, respectively.

It is important to note that the frequency of genotype II among the healthy population in Ukraine was $18 \%$. Among the studied European countries, the highest rate was reported in Poland (Borzyszkowska et al., 2012).

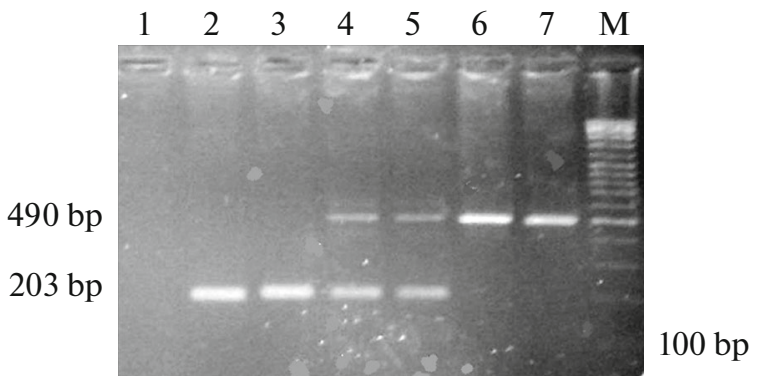

Fig. 1. Electrophoregram of separation of PCR fragments of the $A C E$ gene product (I/D) in $2 \%$ agarose gel. Lane 1negative control, 2, 3-II, 4, 5-I/D, 6, 7-DD, M-molecular weight marker (Ladder 100 b.p.).

While the lowest rate of $15 \%$ was observed in Spanish (Freitas et al., 2008). On the other hand, in the same population the highest COVID-19 incidence rate was 5034 per one million population, while the lowest incidence rate was observed in Slovakia, 284 per million population. One should bear in mind that the frequency of genotype II in the population of Slovakia is one of the highest in the group of the studied European countries reaching 25\% (Siváková et al., 2009). At the same time, the highest mortality rates from COVID-19 were reported in Belgium where the frequency of genotype II is $19 \%$. The lowest mortality rates from COVID-19 were observed in Ukraine where the frequency of genotype II is $18 \%$, while the COVID-19 incidence in the population is 471 per million population. To confirm our hypothesis of the possible protective role of genotype II carriers in SARSCoV-2 infection affecting thus the course of COVID19 disease, we analyzed the correlation between morbidity and mortality per one million population and the frequency of genotype II of the $A C E 1$ gene.

The correlation between the incidence of COVID19 (Fig. 2), mortality from this disease (Fig. 3) and the prevalence of genotype II of the $A C E 1$ gene in the studied populations was assessed using Spearman's rank correlation coefficient $(R)$. A statistically signifi-

Table 1. Distribution of genotypes and allelic variants of I/D polymorphism in the $A C E 1$ gene in the control group of healthy individuals from Ukraine

\begin{tabular}{cc|c}
\hline Locus & Control group, $n=100$ \\
\hline II & Genotype, $n, \%$ \\
ID & $18(0.18)$ \\
DD & $51(0.51)$ \\
& Alleles & $31(0.31)$ \\
I & & 0.435 \\
D & 0.565 \\
\hline
\end{tabular}


Table 2. Genotype II frequencies and morbidity and mortality rates from COVID-19

\begin{tabular}{|c|c|c|c|c|c|c|}
\hline Country & No. of subjects & ACE $1 \mathrm{I} / \mathrm{I}, \%$ & Covid-19 cases & $\begin{array}{c}\text { Case/pop, } \\
\text { n/mill }\end{array}$ & Deaths & $\begin{array}{c}\text { Death/pop, } \\
\text { n/mill }\end{array}$ \\
\hline Ukraine & 100 & 18 & 388715 & 471 & 21676 & 2.67 \\
\hline Hungary & 120 & 27 & 3741 & 386 & 482 & 50 \\
\hline Poland & 632 & 29 & 29392 & 774 & 1247 & 33 \\
\hline Slovakia & 209 & 25 & 1548 & 284 & 284 & 5 \\
\hline Sweden & 59 & 27 & 33188 & 3307 & 3992 & 398 \\
\hline Denmark & 199 & 23 & 11487 & 1990 & 561 & 97 \\
\hline Switzerland & 199 & 25 & 31117 & 3631 & 1938 & 226 \\
\hline United Kingdom & 386 & 21.2 & 258504 & 3828 & 36757 & 544 \\
\hline Netherlands & 61 & 20 & 45265 & 2648 & 5830 & 341 \\
\hline Belgium & 109 & 19 & 56810 & 4923 & 9237 & 800 \\
\hline Germany & 172 & 20.1 & 179986 & 2155 & 8261 & 99 \\
\hline France & 450 & 17.6 & 182036 & 2795 & 28218 & 433 \\
\hline Spain & 266 & 15 & 235290 & 5034 & 28678 & 614 \\
\hline Italy & 468 & 16.6 & 229327 & 3787 & 32735 & 541 \\
\hline Portugal & 510 & 16 & 36690 & 3569 & 1517 & 148 \\
\hline
\end{tabular}

cant negative correlation between morbidity and prevalence of genotype II $(R=-0.53, p<0.05)$ has been determined, the same trend being observed for the relationship between mortality from COVID-19 and the prevalence of genotype II in the populations. However, the correlation coefficient $(R=-0.47, p=0.09)$ in the latter case is not statistically significant.

The presence of genotype II may affect the incidence and the clinical course of COVID-19, similar patterns have been noted in studies by other authors for the population of Europe and the Middle East. This study also revealed a higher susceptibility to SARS infection-CoV-2 of the population of these countries compared to the population of Asia (Naoki Y. et al., 2020). It should be noted that the established relationship between the frequency of genotype II and the incidence of COVID-19 is in agreement with the patterns reported of other authors (Naoki Y. et al., 2020; Joris and Delanghe et al., 2020). As to the relationship between mortality from COVID-19 and the genotype II carriers, no statistically significant correlation was found for the population of Ukraine, neighboring border countries such as Poland, Slovakia, Hungary and other European countries (Sweden, Denmark, Belgium, Italy, Spain, France, Switzerland, the Netherlands, Portugal, Germany, Great Britain).

The differences between COVID-19 morbidity/mortality rates across Europe and, especially, in Asia can be explained by both different sociocultural pattern in pandemic behavior and different anti-epidemic measures as well as different quality of medical care. However, the correlations between the prevalence of differ-

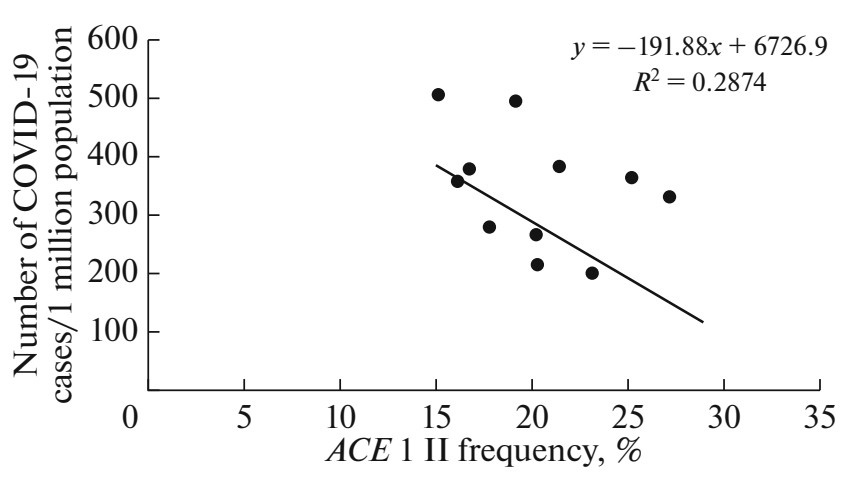

Fig. 2. Relationship between incidence of COVID-19 and the prevalence of genotype II of the ACE1 gene (\%) in Ukraine and European countries.

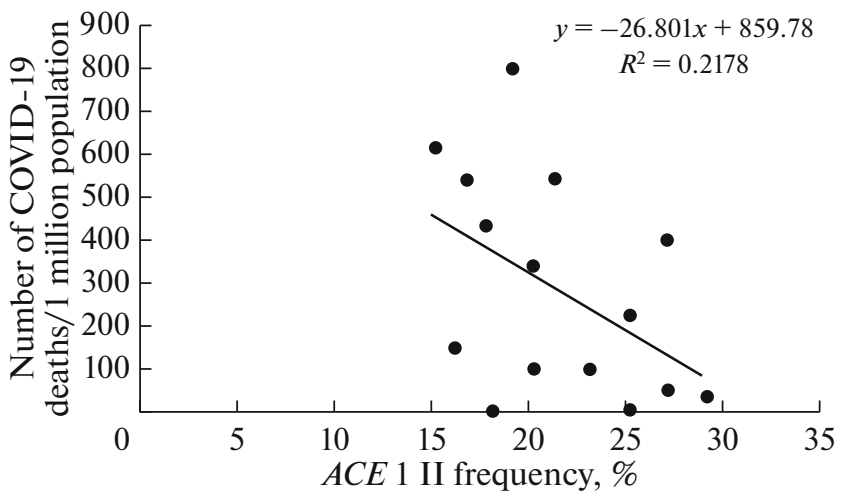

Fig. 3. Relationship between mortality from COVID-19 and prevalence of genotype II of the $A C E 1$ gene (\%) in Ukraine and European countries. 
ent genotypes by ACE1 I/D polymorphism and morbidity, mortality from COVID-19 found in this and other studies suggest that ACE1 I/D polymorphism might be an informative genetic marker of SARS$\mathrm{CoV}-2$ to predict the prevalence in the population. On the other hand, the recently obtained numerical data establish in a correlation between allelic polymorphism ACE1 I/D and cardiovascular disease, inflammation and immune processes lay a groundwork for further research of markers for prognosis of severity COVID-19 (Manci Li et al., 2021). Studies of other genes involved in the pathogenicity of SARS-CoV-2 such as ACE2b CTSL, TMPRSS have yielded conflicting results regarding their relationship with morbidity, severity, and mortality from COVID-19 (Anastassopoulou C. et al., 2020; Brest P. et al., 2020; Naoki Y. et al., 2020).

The distribution of genotypes and frequency of allelic variants by insertion/deletion (I/D) polymorphism in the 16th intron of the $A C E 1$ gene in the population of healthy individuals of Ukraine has been established. The patterns of the negative correlation between morbidity, mortality from COVID-19 and the prevalence of inertia (II) homozygotes by $A C E 1$ gene polymorphism in populations of Ukraine and other European countries reveled in this and other studies reflect multi-vector relationships between the expression level of this gene and the pathogenesis of COVID-19. Further studies of the role of allelic variants of the $A C E 1$ gene in the evolution of severe disease and complications from COVID-19 are required for the development of prognostic genetic markers for personalized therapy.

Ethical approval for the study was obtained from the bioethics committee of the State Institution "Institute of Pediatrics, Obstetrics and Gynecology named after Academician O.M. Lukyanova, National Academy of Medical Sciences of Ukraine", protocol no. 28 (15.10.2020). Informed consent was obtained from patients.

\section{FUNDING}

This work was funded by the NRFU "Investigate the importance of medical, biological and sociological factors in the spread of coronavirus infection among women and children in Ukraine" with state registration no. 0120U104508.

\section{COMPLIANCE WITH ETHICAL STANDARDS}

Conflict of interest. The authors declare that they have no conflict of interest.

Statement of compliance with standards of research involving humans as subjects. All procedures performed in studies involving human participants were in accordance with the ethical standards of the institutional and/or national research committee and with the 1964 Helsinki Declaration and its later amendments or comparable ethical standards.
Informed consent was obtained from all individual participants involved in the study.

\section{DECLARATION OF COMPETING INTEREST}

The authors declare that they have no known competing financial interests or personal relationships that could have appeared to influence the work reported in this paper.

\section{REFERENCES}

Anastassopoulou, C., Gkizarioti, Z., and Patrinos, G.P., Human genetic factors associated with susceptibility to SARS-CoV-2 infection and COVID-19 disease severity, Hum. Genomics, 2020, vol. 4, pp. 1-8. https://doi.org/10.1186/s40246-020-00290-4

Bellone, M. and Calvisi, S.L., ACE polymorphism and COVID-19-related mortality in Europe, Mol. Med. (Berl.), 2020, vol. 98, pp. 1505-1509. https://doi.org/10.1007/s00109-020-01981-0

Borzyszkowska, J., Stanislawska-Sachadyn, A., Wirtwein, M., Sobiczewski, W., Ciecwierz, D., Targonski, R., Gruchala, M., Rynkiewicz, A., and Limon, J., Angiotensin converting enzyme gene polymorphism is associated with severity of coronary artery disease in men with high total cholesterol levels, J. Appl. Genet., 2012, vol. 53, pp. $175-182$. https://doi.org/10.1007/s13353-012-0083-3

Brest, P., Refae, S., Mograbi, B., Hofman, P., and Milano, G., Host polymorphisms may impact SARS-CoV-2 infectivity, Trends Genet., 2020, vol. 36, no. 11, pp. 813-815. https://doi.org/10.1016/j.tig.2020.08.003

Freitas, A.I., Mendonca, I., Briyn, M., Sequeira, M.M., Reis, R.P., Carracedo, A., and Brehm, A., RAS gene polymorphisms, classical risk factors and the advent of coronary artery disease in the Portuguese population, BMC Cardiovasc. Disord., 2008, vol. 8, p. 15. http://www.biomed-central.com/1471-2261/8/15.

Hoffmann, M., Kleine-Weber, H., Schroeder, S., Krüger, N., Herrler, T., Erichsen, S., et al., SARS-CoV-2 cell entry depends on ACE2 and TMPRSS2 and is blocked by a clinically proven protease inhibitor, Cell, 2020, vol. 181, no. 2, pp. 271-280. e8.

https://doi.org/10.1016/j.cell.2020.02.052

Itoyama, S., et al., ACE1 polymorphism and progression of SARS, Biochem. Biophys. Res. Commun., 2004, vol. 323, no. 3 .

https://doi.org/10.1016/j.bbrc.2004.08.208

Delanghe, J.R., Speeckaert, M.M., and de Buyzere, M.L., COVID-19 infections are also affected by human ACE1 D/I polymorphism, Clin. Chem. Lab. Med., 2020, vol. 58 , no. 7 , pp. $1125-1126$.

https://doi.org/10.1515/cclm-2020-0425

Li, W., Moore, M.J., Vasilieva, N., Sui, J., Wong, S.K., Berne, M.A., et al., Angiotensin-converting enzyme 2 is a functional receptor for the SARS coronavirus, $\mathrm{Na}$ ture, 2003, vol. 426, no. 6965, pp. 450-454.

Manci Li, Schifanella, L., and Larsen, P.A., Alu retrotransposons and COVID-19 susceptibility and morbidity, Hum. Genomics, 2021, vol. 15, no. 1, p. 2. https://doi.org/10.1186/s40246-020-00299-9 
Zhu, N., Zhang, D., Wang, W., Li, X., Yang, B., Song, J., Zhao, X., Huang, B., Shi, W., Lu, R., Niu, P., Zhan, F., et al., A novel coronavirus from patients with pneumonia in China, 2019, N. Engl. J. Med., 2020, vol. 382, pp. 727-733.

https://doi.org/10.1056/NEJMoa2001017

Naoki, Y., Yasuo, A., Nao, N., Rain, Y., Georg, B., Takashi, G., Kunitada, S., and Masashi, M., SARS-CoV-2 infections and COVID-19 mortalities strongly correlate with ACE1 I/D genotype, Gene, 2020, vol. 758, p. 144944. https://doi.org/10.1016/j.gene.2020.144944

Ned, R.M., et al., The ACE I/D polymorphism in US adults: limited evidence of association with hypertension-related traits and sex-specific effects by race/ethnicity, Am. J. Hypertens., 2012, vol. 25, no. 2. https://doi.org/10.1038/ajh.2011.182

Novelli, A., Biancolella, M., Borgiani, P., et al., Analysis of ACE2 genetic variants in 131 Italian SARS-CoV-2-positive patients, Hum. Genomics, 2020, vol. 14, p. 29. https://doi.org/10.1186/s40246-020-00279-z

Ren, L.L., Wang, Y.M., Wu, Z.Q., et al., Identification of novel coronavirus causing severe pneumonia in human: a descriptive study, Chin. Med. J., 2020, vol. 133, no. 9, pp. $1015-1024$. https://doi.org/10.1097/CM9.0000000000000722

Rigat, B., Hubert, C., Alhenc-Gelas, F., Cambien, F., Corvol, P., and Soubrier, F., An insertion/deletion polymorphism in the angiotensin I-converting enzyme gene accounting for half the variance of serum enzyme levels, J. Clin. Invest., 1990, vol. 86, no. 4, pp. 1343-1346. https://doi.org/10.1172/JCI114844

Saab, Y.B., Gard, P.R., and Overall, A.D.J., The geographic distribution of the ACE II genotype: a novel finding, Genet. Res. Camb., 2007, vol. 89, pp. 259-267.

Siváková, D., Lajdová, A., Basistová, Z., Cvácelová, M., and Blazícek, P., ACE insertion/deletion polymorphism and its relationship to the components of metabolic syndrome in elderly Slovaks, Anthropol. Anz., 2009, vol. 67, pp. 1-11.

https://doi.org/10.1127/0003-5548/2009/0001

Tiret, L., et al., Evidence, from combined segregation and linkage analysis, that a variant of the angiotensin I-converting enzyme (ACE) gene controls plasma ACE levels, Am. J. Hum. Genet., 1992, vol. 51, no. 1.

Velavan, T.P. and Meyer, C.G., The COVID-19 epidemic, Trop. Med. Inter. Health, 2020, vol. 25, no. 3. https://doi.org/10.1111/tmi.13383 